\title{
Gallbladder Obstruction, CTCAE
}

National Cancer Institute

\section{Source}

National Cancer Institute. Gallibladder Obstruction, CT CAE. NCI Thesaurus. Code C57810.

A disorder characterized by blockage of the normal flow of the contents of the gallbladder. 